\title{
Cardiac arrest patients have an impaired immune response, which is not influenced by induced hypothermia
}

Charlotte J Beurskens ${ }^{1,2,4^{*}}$, Janneke Horn², Anita M Tuip de Boer ${ }^{1}$, Marcus J Schultz ${ }^{1,2}$, Ester MM van Leeuwen ${ }^{3}$, Margreeth B Vroom ${ }^{2}$ and Nicole P Juffermans ${ }^{1,2}$

\begin{abstract}
Introduction: Induced hypothermia is increasingly applied as a therapeutic intervention in ICUs. One of the underlying mechanisms of the beneficial effects of hypothermia is proposed to be reduction of the inflammatory response. However, a fear of reducing the inflammatory response is an increased infection risk. Therefore, we studied the effect of induced hypothermia on immune response after cardiac arrest.
\end{abstract}

Methods: A prospective observational cohort study in a mixed surgical-medical ICU. Patients admitted at the ICU after surviving cardiac arrest were included and during 24 hours body temperature was strictly regulated at $33^{\circ} \mathrm{C}$ or $36^{\circ} \mathrm{C}$. Blood was drawn at three time points: after reaching target temperature, at the end of the target temperature protocol and after rewarming to $37^{\circ} \mathrm{C}$. Plasma cytokine levels and response of blood leucocytes to stimulation with toll-like receptor (TLR) ligands lipopolysaccharide (LPS) from Gram-negative bacteria and lipoteicoic acid (LTA) from Gram-positive bacteria were measured. Also, monocyte HLA-DR expression was determined.

Results: In total, 20 patients were enrolled in the study. Compared to healthy controls, cardiac arrest patients kept at $36^{\circ} \mathrm{C}(n=9)$ had increased plasma cytokines levels, which was not apparent in patients kept at $33^{\circ} \mathrm{C}(n=11)$. Immune response to TLR ligands in patients after cardiac arrest was generally reduced and associated with lower HLA-DR expression. Patients kept at $33^{\circ} \mathrm{C}$ had preserved ability of immune cells to respond to LPS and LTA compared to patients kept at $36^{\circ} \mathrm{C}$. These differences disappeared over time. HLA-DR expression did not differ between $33^{\circ} \mathrm{C}$ and $36^{\circ} \mathrm{C}$.

Conclusions: Patients after cardiac arrest have a modest systemic inflammatory response compared to healthy controls, associated with lower HLA-DR expression and attenuated immune response to Gram-negative and Gram-positive antigens, the latter indicative of an impaired immune response to bacteria. Patients with a body temperature of $33^{\circ} \mathrm{C}$ did not differ from patients with a body temperature of $36^{\circ} \mathrm{C}$, suggesting induced hypothermia does not affect immune response in patients with cardiac arrest.

Trial registration: ClinicalTrials.gov NCT01020916, registered 25 November 2009

\footnotetext{
* Correspondence: c.j.beurskens@amc.nl

${ }^{1}$ Laboratory of Experimental Intensive Care and Anaesthesiology, Academic

Medical Center, University of Amsterdam, Meibergdreef 9, 1105 AZ,

Amsterdam, Netherlands

${ }^{2}$ Department of Intensive Care, Academic Medical Center, University of

Amsterdam, Meibergdreef 9, 1105 AZ, Amsterdam, Netherlands

Full list of author information is available at the end of the article
} 


\section{Introduction}

Induced hypothermia is applied clinically to reduce ischemia-reperfusion injury during operative procedures and following cardiac arrest [1-3]. In cardiopulmonary surgery, hypothermia is associated with improved neurological outcome $[4,5]$. Also, avoiding hyperthermia by controlling body temperature is associated with a favourable neurologic function in survivors of cardiac arrest [6], as well as with earlier shock reversal in septic shock patients [7]. Inhibition of the exaggerated systemic inflammatory response syndrome (SIRS) is thought to be one of the mechanisms through which temperature management can mitigate the harmful effects of ischemia-reperfusion. In a pig model of cardiac arrest, hypothermia reduced expression of pro-inflammatory cytokines within the brain [8]. Also in other models of hyper-inflammatory conditions, hypothermia reduced organ failure associated with a decrease of the inflammatory response [9-15]. Also in infectious disease models, hypothermia was associated with a reduction in organ failure $[9,16]$. Thereby, hypothermia may mitigate harm caused by an 'overshoot' of a systemic inflammatory response.

On the other hand, an adequate adaptive host immune response to pathogens and infection is crucial [17]. Fever has long been considered an important factor for optimal antimicrobial host defense, [18-21].

Hypothermia inhibits immune response [22], with delayed generation of pro-inflammatory cytokines by monocytes [23] and reduction of neutrophil and monocyte migration $[24,25]$. The consequence of inhibiting host immune response by induced hypothermia may be a higher infection risk. In particular, patients shortly after a cardiac arrest suffer from a dysregulated production of cytokines and may therefore be susceptible to nosocomial infection [26]. Two randomized trials in cardiac arrest patients reported no increased overall infection rates associated with hypothermia [1,27], although a trend towards more infection could be noted [27]. Also trials in traumatic brain injury have not reported increased infection rate following hypothermia [28,29], although not all studies are consistent [30]. In addition, prolonged hypothermia (for more than 48 hours) did not increase risk of infection in patients with brain injury [31-33], taking into account that some of these patients received selective decontamination of the digestive tract [32].

However, a recent systematic review in patients enrolled in randomized controlled clinical trials of therapeutic hypothermia for any indication, showed an association of hypothermia with increased prevalence of pneumonia and sepsis, although overall infection rate was not affected [34]. Taken together, the effect of hypothermia on the risk of infections is unclear. Patient studies describing the effect of induced hypothermia specifically on the innate immune response are scarce and studies lack an adequate control group [35]. Recently, the Temperature Target Management (TTM) trial was concluded, in which cardiac arrest patients were randomized between maintaining body temperature at $33^{\circ} \mathrm{C}$ or at $36^{\circ} \mathrm{C}$ [27]. In this predefined substudy of the TTM trial, we investigated the effect of induced hypothermia on the innate immune response to toll-like receptor (TLR) ligands. In humans, TLRs are critical in the first host immune response to pathogens by mediating cytokine secretion [36]. In addition, we measured human leukocyte antigen-DR (HLA-DR) surface expression on monocytes, as low HLA-DR expression is associated with secondary infection and mortality in critically ill patients $[37,38]$ and hypothermia was shown to reduce HLA-DR expression in vitro [39]. We hypothesized that SIRS is reduced in patients with a target temperature of $33^{\circ} \mathrm{C}$ compared to patients with a target temperature of $36^{\circ} \mathrm{C}$, but that hypothermia does not affect the immune response to pathogen-associated molecular patterns (lipopolysaccharide (LPS) and lipoteicoic acid (LTA)).

\section{Methods}

\section{Patient inclusion}

The study was approved by the local medical ethics committee of the Academic Medical Center, University of Amsterdam, the Netherlands (NL32522.018.10) and conducted in concordance with the principles of the Declaration of Helsinki and good clinical practice. From January 2011 until October 2012, adult patients admitted to the mixed surgical-medical intensive care unit (ICU) of a tertiary referral center in Amsterdam, the Netherlands after out-of-hospital cardiac arrest with a Glasgow Coma Score $<8$ and treated with therapeutic hypothermia $\left(33^{\circ} \mathrm{C}\right)$ for 24 hours, were included in our study after their relatives gave informed consent. From March 2011, our center started enrollment in the TTM trial, patients who enrolled in the TTM trial were only included for our substudy after additional informed consent was obtained from the relatives. Exclusion criteria were pregnancy, out-of-hospital cardiac arrest of presumed non-cardiac cause, in-hospital cardiac arrest, known bleeding diathesis, suspected or confirmed acute intracranial bleeding, suspected or confirmed acute stroke, temperature on admission $<30^{\circ} \mathrm{C}$, unwitnessed asystole, persistent cardiogenic shock, known limitations in therapy, known disease making 180-day survival unlikely, known pre-arrest cerebral performance category 3 or $4,>240$ minutes from return of spontaneous circulation (ROSC) to randomisation [27]. Patients included prior to the TTM trial $(\mathrm{n}=8$; target temperature 32 to $\left.34^{\circ} \mathrm{C}\right)$ and during the TTM trial $\left(\mathrm{n}=12,3\right.$ in the $33^{\circ} \mathrm{C}$ 
group and 9 in the $36^{\circ} \mathrm{C}$ group) did not differ in patients characteristics, Acute Physiology and Chronic Health Evaluation (APACHE) III, Simplified Acute Physiology Score (SAPS) II score, time to ROSC and cause of cardiac arrest (data not shown). A total of 20 patients were included, of whom 11 with a target temperature of $33^{\circ} \mathrm{C}$ and 9 patients with a target temperature of $36^{\circ} \mathrm{C}$. Healthy volunteers were recruited and included after informed consent for a single blood donation $(n=4$, mean age 28 years, $75 \%$ female).

\section{Study procedure}

Patients included in our study received standard postresuscitation care according to the current best practice or the post-resuscitation protocol of the TTM trial [27], including 24 hours of target temperature management to achieve a core body temperature of either $33^{\circ} \mathrm{C}$ or $36^{\circ} \mathrm{C}$ with the use of ice-cold saline (maximum $1 \mathrm{~L}$ ) and a cooling device (Blanket roll, Cincinnatti Sub-Zero, Cincinnatti, $\mathrm{OH}, \mathrm{USA})$. Temperature was measured using a bladder catheter. All patients were sedated with propofol, mechanically ventilated in a pressure-controlled mode and selective digestive tract decontamination was administered by intestinal and oropharyngeal application of topical, non-absorbable antibiotics (100 $\mathrm{mg}$ polymyxine E, 80 $\mathrm{mg}$ tobramycine, $500 \mathrm{mg}$ amphothericine B) during the whole ICU stay in combination with intravenous administration of cefotaxime during the first four days of ICU stay. Patients received either anticoagulant therapy as deemed appropriate or thrombosis prophylaxis. Patients were not fed. Blood was drawn at three time points: after reaching target temperature $\left(33^{\circ} \mathrm{C}\right.$ or $\left.36^{\circ} \mathrm{C} ; \mathrm{T}=1\right)$, at the end of the target temperature protocol $(\mathrm{T}=2)$ and after reaching $37^{\circ} \mathrm{C}(\mathrm{T}=3)$. Healthy volunteers donated only once.

\section{Measurements and data collection}

Data from the patient data monitoring system were collected, including previous medical history, age, gender, weight, length, maximal leukocyte count, APACHE III, SAPS II score, as registered in the Dutch National Intensive Care Evaluation [40].

Serum levels of interleukin (IL)-1 $\beta$, IL-1RA, IL-8, IL-10, macrophage inflammatory proteins (MIP)- 1 , monocyte chemotactic protein (MCP)-1 and soluble CD40 ligand were determined by Luminex, according to the manufacturer's instructions (Merck Millipore Chemicals BV, Amsterdam, the Netherlands). Serum levels of IL-6 and tumor necrosis factor (TNF)- $\alpha$ were determined by enzyme-linked immunosorbent assay (ELISA), according to the manufacturer's instructions (R\&D Systems, Abingdon, United Kingdom).

\section{Whole blood stimulation}

The response of blood leucocytes to stimulation with TLR ligands was determined in a whole blood stimulation system. Immediately after drawing, blood was diluted 1:1 with RPMI and stimulated with LPS (100 ng/ $\mathrm{ml}$; Sigma-Aldrich, Steinheim, Germany) or LTA $(10 \mu \mathrm{g} /$ ml; Invivogen, San Diego, CA, USA) as bacterial antigens of respectively Gram-negative and Gram-positive bacteria. After 2 or 24 hours stimulation in a $37^{\circ} \mathrm{C}$ incubator with $5 \% \mathrm{CO}_{2}$, whole blood was centrifuged at $600 \mathrm{~g}$ for 10 minutes at $4^{\circ} \mathrm{C}$. Supernatant was stored at $-80^{\circ} \mathrm{C}$ and levels of IL- 6 and TNF- $\alpha$ were determined by ELISA, according to the manufacturer's instructions (R\&D Systems).

\section{HLA-DR expression}

HLA-DR expression on monocytes was analysed by fluorescence-activated cell sorter after labelling by incubation with HLA-DR-FITC and CD14-PE monoclonal antibodies (Becton Dickinson, Erembogem, Belgium). Erythrocytes were lysed with lysis buffer (Becton Dickinson BV, Breda, the Netherlands) and the debris was washed away. The remaining leukocytes were fixated with $1 \%$ paraformaldehyde. The final flow cytometric analysis was done, using a flow cytometry (Becton Dickinson BV, Breda, the Netherlands). HLA-DR expression was measured on CD14-bright monocytes, which have mainly anti-inflammatory properties [41] and CD14-dull monocytes, which are more pro-inflammatory, since they selectively induce production of cytokines in response to viruses and immune complexes containing nucleic acids [42]. To compare patient samples measured at different time points, a standard series of quantum beads, which are labelled with a known quantity of FITC fluorescent label (Quantum FITC-5 MESF (Premix), Bangs Laboratories, Fishers, IN, USA) was analysed simultaneously with each measurement. Therefore, HLA-DR expression could be expressed in molecules of equivalent soluble fluorochrome (MESF) units.

\section{Statistical analysis}

Data are expressed by mean \pm standard deviation (SD) in the table and as median \pm range in the figures, depending on distribution of the data. Differences between the $33^{\circ} \mathrm{C}$ and $36^{\circ} \mathrm{C}$ groups were compared using an unpaired $t$ test or a Mann-Whitney $U$ test, depending on distribution of the data. The effect of temperature over time was compared using a repeated measurement analysis of variance (ANOVA) or a Friedman test with either a Bonferroni's or Dunn's multiple comparison test correction. Differences between healthy volunteers and patients with a target temperature of either $33^{\circ} \mathrm{C}$ or $36^{\circ} \mathrm{C}$ over time were compared using a one-way ANOVA or Kruskal-Wallis test, with either a Bonferroni's or Dunn's 
multiple comparison test, depending on distribution of the data. Statistical significance was set at $P<0.05$.

\section{Results}

Patient characteristics

Patients in the $33^{\circ} \mathrm{C}$ and $36^{\circ} \mathrm{C}$ groups did not differ in previous medical history or disease severity (Table 1 ). After reaching target temperature at $\mathrm{T}=1$, body temperature was $33.2 \pm 0.7^{\circ} \mathrm{C}$ in patients with a target temperature of $33^{\circ} \mathrm{C}$ and $35.6 \pm 0.9^{\circ} \mathrm{C}$ in patients with a target temperature of $36^{\circ} \mathrm{C}(P=0.002)$. At $\mathrm{T}=1$, plasma samples could not be collected from four patients. One patient with a target temperature of $33^{\circ} \mathrm{C}$ died before the last time point of blood sampling $(\mathrm{T}=3)$. A confirmed infection within 24 hours after ICU admittance occurred in two patients, one patient in each group (Table 1).

\section{The effect of hypothermia on the SIRS reaction}

Baseline inflammatory response was measured in plasma cytokines levels (Figure 1). Levels of IL-1RA, IL-8, IL-10 and MCP-1 showed an increase in the patient group with a target temperature of $36^{\circ} \mathrm{C}$ compared to healthy controls, which was not apparent in the $33^{\circ} \mathrm{C}$ group. Levels of IL-1RA, but not of other cytokines, decreased

Table 1 Baseline characteristics of 11 patients with a target temperature of $33^{\circ} \mathrm{C}$ compared 9 patients with a target temperature of $36^{\circ} \mathrm{C}$, after reaching target temperature

\begin{tabular}{|c|c|c|c|}
\hline & $33^{\circ} \mathrm{C}$ & $36^{\circ} \mathrm{C}$ & $P$ value \\
\hline Gender (male/female) & $8 / 3$ & $8 / 1$ & \\
\hline Age (years) & $64 \pm 15$ & $61 \pm 15$ & 0.70 \\
\hline Length $(\mathrm{cm})$ & $173 \pm 12$ & $178 \pm 7$ & 0.27 \\
\hline Weight (kg) & $81 \pm 24$ & $81 \pm 13$ & 0.95 \\
\hline Maximal leukocyte count & $15.8 \pm 4.9$ & $16.1 \pm 4.0$ & 0.92 \\
\hline SAPS II score & $54 \pm 18$ & $59 \pm 18$ & 0.58 \\
\hline APACHE III score & $80 \pm 44$ & $88 \pm 34$ & 0.71 \\
\hline \multicolumn{4}{|l|}{ Previous medical history } \\
\hline Chronic cardiovascular insufficiency & 1 & 0 & \\
\hline Arrhythmia & 1 & 0 & \\
\hline Cerebrovascular accident & 1 & 0 & \\
\hline Chronic kidney failure & 0 & 0 & \\
\hline Diabetes & 1 & 1 & \\
\hline COPD & 1 & 0 & \\
\hline Chronic respiratory failure & 0 & 0 & \\
\hline Cirrhosis & 0 & 0 & \\
\hline AIDS & 0 & 0 & \\
\hline Immune insufficiency & 0 & 0 & \\
\hline Malignancy & 0 & 0 & \\
\hline
\end{tabular}

Data expressed as mean \pm SD. APACHE: Acute Physiology and Chronic Health Evaluation; SAPS: Simplified Acute Physiology Score; COPD: chronic obstructive pulmonary disease. after 24 hours of temperature management protocol ( $\mathrm{T}=1$ vs. $\mathrm{T}=2$; Figure 1 ) in the group with a target temperature of $36^{\circ} \mathrm{C}$. Levels of IL-1RA, IL-8, IL-10 and MCP-1 were higher in the $36^{\circ} \mathrm{C}$ group compared to the $33^{\circ} \mathrm{C}$ group shortly after reaching target temperature, but these differences disappeared during temperature management over time ( $T=1$; Figure 1). Plasma levels of IL-1 $\beta$, MIP-1, soluble CD40 ligand and TNF- $\alpha$ levels were not increased in patients compared to healthy controls, nor were there differences between the $33^{\circ} \mathrm{C}$ group and the $36^{\circ} \mathrm{C}$ group.

\section{The effect of hypothermia on the immune response to TLR ligands}

Results of whole blood stimulated for two hours were not different from 24 hours stimulation. Therefore, only the results of 24 hours stimulation are shown (Figure 2).

\section{Response to LPS}

The immune response to stimulation with Gramnegative antigen LPS resulted in lower levels of IL- 6 and TNF- $\alpha$ in patients of the $36^{\circ} \mathrm{C}$ group compared to healthy controls, which increased towards the end of the temperature management protocol in the group with a target temperature of $36^{\circ} \mathrm{C}$ (Figure 2, upper panel; $\mathrm{T}=1$ vs. $\mathrm{T}=3$ ). This increase was not observed in the $33^{\circ} \mathrm{C}$ group. TNF- $\alpha$ levels were decreased in the $36^{\circ} \mathrm{C}$ group compared to the $33^{\circ} \mathrm{C}$ group at baseline. However, no significant differences between the groups appeared during the 24 hours of temperature management and after rewarming.

\section{Response to LTA}

Production of IL-6 did not differ between patient groups and healthy controls, nor were there differences over time between the $33^{\circ} \mathrm{C}$ and $36^{\circ} \mathrm{C}$ groups (Figure 2, lower panel). The TNF production in response to stimulation with the Gram-positive antigen LTA was decreased in patients with a target temperature of $36^{\circ} \mathrm{C}$ compared to healthy controls at the start of the temperature management and increased again after regaining normothermia $(\mathrm{T}=1$ vs. $\mathrm{T}=3$; Figure 2). TNF- $\alpha$ level was also lower in the $36^{\circ} \mathrm{C}$ group compared to the $33^{\circ} \mathrm{C}$ group at $\mathrm{T}=1$, but this difference between groups disappeared during temperature management over time.

\section{The effect of hypothermia on HLA-DR expression}

HLA-DR expression on CD14-bright monocytes was reduced in patients compared to healthy controls at all time points for both the $33^{\circ} \mathrm{C}$ and $36^{\circ} \mathrm{C}$ group (Figure 3). HLA-DR expression on both bright and dull monocytes further decreased over time ( $\mathrm{T}=1$ vs. $\mathrm{T}=3$; Figure 3 ). HLA-DR expression showed no differences between the $33^{\circ} \mathrm{C}$ and $36^{\circ} \mathrm{C}$ groups. 


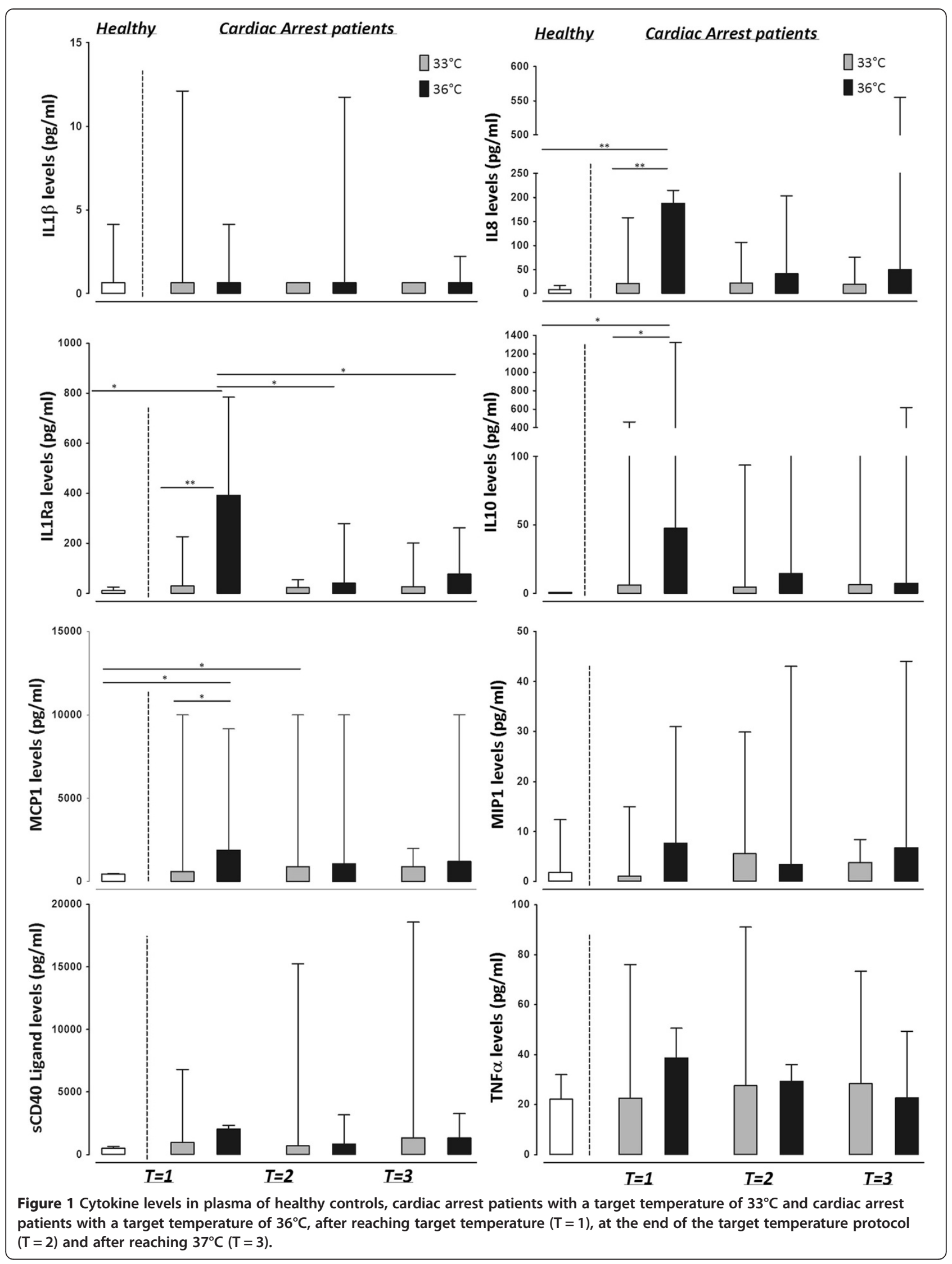




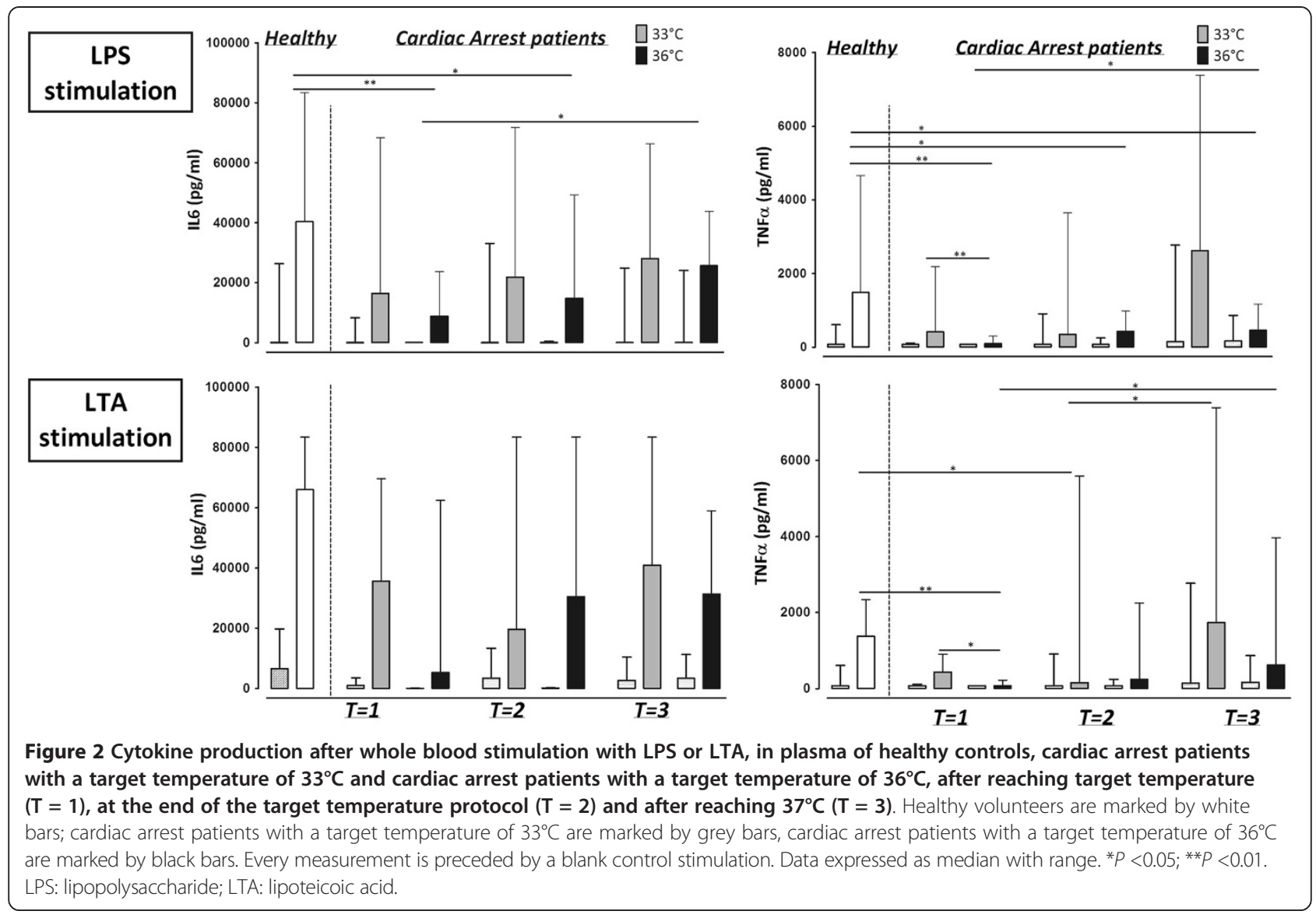

\section{Discussion}

Patients after cardiac arrest demonstrate a SIRS compared to healthy controls, which was most noted for those who were kept at $36^{\circ} \mathrm{C}$ and blunted for those who were cooled to $33^{\circ} \mathrm{C}$. This SIRS reaction was associated with lower HLA-DR expression and an attenuated immune response to Gram-negative and Gram-positive antigens compared to healthy controls. Between patients with a targeted body temperature of $33^{\circ} \mathrm{C}$ compared to $36^{\circ} \mathrm{C}$, there were no differences in immune response to the bacterial antigens.

An increased systemic inflammatory response following cardiac arrest compared to healthy controls has been shown before [26]. The inflammatory response in cardiac arrest patients treated with induced hypothermia, was previously studied by Bisschops et al., showing a temporary increase of IL-6 levels during hypothermia and increased levels of IL-8 and MCP-1 compared to baseline [35], with levels largely comparable to our patients. Anti-inflammatory cytokines IL-1RA and IL-10 were unaltered compared to baseline [35]. However, in this study, effects of body temperature could not be dissected from effects of ischemia-reperfusion injury following cardiac arrest. Our study expands on these findings by including a normothermic control group over time. We found that initial cytokine levels were reduced in patients with a target temperature of $33^{\circ} \mathrm{C}$ compared to $36^{\circ} \mathrm{C}$, although differences were small. This decrease in inflammatory response is in line with multiple experimental studies demonstrating an inhibitory effect of hypothermia on cytokine levels [10-13,23]. However, at the end of the 24 hours of the temperature management protocol, there were no differences between both groups in plasma cytokine levels. Thereby, any effect of hypothermia on systemic inflammatory response seems temporary.

The systemic inflammatory response in patients was accompanied by an initial decreased ability of immune cells to respond to TLR ligands LPS and LTA, although not all cytokines were affected. The ability to generate an immune response can also be measured by HLA-DR expression. Of interest, we found a clear reduction in the expression of HLA-DR following cardiac arrest, compared to healthy controls. A blunted host immune response to TLR ligands and a decreased HLA-DR expression have been shown before in septic shock patients $[38,43]$, which is thought to contribute to an increased risk of nosocomial infection. To the best of our knowledge, this attenuated immune response to bacterial antigens after cardiac arrest has not been reported before. 

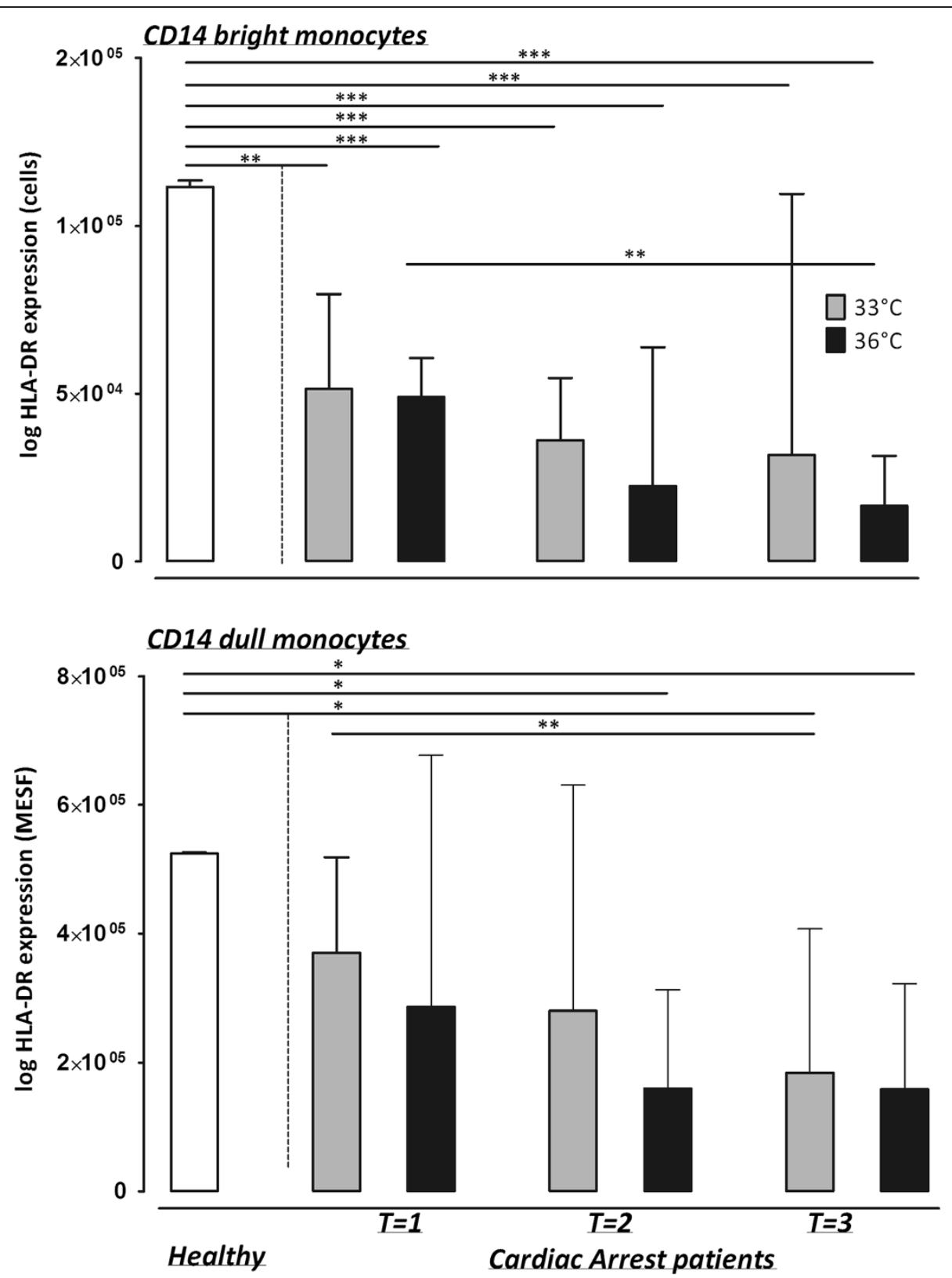

Figure 3 HLA-DR expression on bright and dull monocytes in plasma of healthy controls, cardiac arrest patients with a target temperature of $33^{\circ} \mathrm{C}$ and cardiac arrest patients with a target temperature of $36^{\circ} \mathrm{C}$, after reaching target temperature $(T=1)$, at the end of the target temperature protocol $(T=2)$ and after reaching $37^{\circ} \mathrm{C}(T=3)$. HLA-DR: human leukocyte antigen-DR.

Decreased HLA-DR expression together with a blunted response to TLR ligands suggests that also cardiac arrest patients have an impaired immune response to pathogens. In line with this, nosocomial infection occurs in up to 50 to $65 \%$ of cardiac arrest patients [44-46]. Thereby, cardiac arrest patients should be closely monitored for the development of nosocomial infection. Whether prophylactic antibiotics are warranted in this patient group remains to be determined.
To investigate effects of induced hypothermia on immune response in cardiac arrest patients, our study provided an appropriate experimental setting in a more or less homogenous patient population. We found that the decreased ability of immune cells to produce TNF- $\alpha$ in response to TLR ligands was more prominent in patients with a target temperature of $36^{\circ} \mathrm{C}$ compared to $33^{\circ} \mathrm{C}$. Thereby, hypothermia does not seem to have an inhibitory effect on immune response to TLR ligands compared to 
normothermia. Also, we found no differences in HLA-DR expression between the $33^{\circ} \mathrm{C}$ and $36^{\circ} \mathrm{C}$ groups at any time points. These results are in line with the TTM trial, which found no significant differences in infection rate between the $33^{\circ} \mathrm{C}$ and $36^{\circ} \mathrm{C}$ groups in a large cohort of cardiac arrest patients [27]. In contrast, a previous study in cardiac arrest patients found that induced hypothermia was an independent risk factor for infection [44]. However, that study lacked a normothermic control group. Also, a metaanalysis suggests that hypothermia increases risk of infection, but in a very heterogeneous patient population [34]. Taken together, our results suggest that having had a cardiac arrest may render the patient susceptible to infection by a decreased immune response, but this risk of infection is not further increased by induced (mild) hypothermia. Whether the immune response is hampered at temperatures below $33^{\circ} \mathrm{C}$ cannot be dissected from this study [47].

Limitations of our study are small sample size. However, larger sample sizes with these kinds of investigations including whole blood stimulations are intricate, since they are labour-intensive and expensive. However, our sample size is comparable to previous studies $[32,35]$. Also, healthy controls were not age-matched to patients, which may have affected the immune response. Lastly, the inclusion period was extensive, but our standard of care protocol did not undergo relevant changes during this time period.

The relevance of our findings is that lowering body temperature may be done safely without compromising the immune response in patient groups who are thought to benefit from regulating body temperature. This may be especially interesting for those patients who suffer from an increased inflammatory response. Currently, a large trial on hypothermia in sepsis patients is ongoing (Trial number: NCT01455116).

\section{Conclusions}

Patients after cardiac arrest have a modest systemic inflammatory response compared to healthy controls. Cardiac arrest was associated with lower HLA-DR expression and attenuated immune response to Gramnegative and Gram-positive antigens, indicative of an impaired immune response. A body temperature of $33^{\circ} \mathrm{C}$ did not influence immune reaction compared to $36^{\circ} \mathrm{C}$, suggesting that induced hypothermia in itself does not affect immune response.

\section{Key messages}

- Cardiac arrest patients have a decreased systemic inflammatory response compared to healthy controls
- However, hypothermia to $33^{\circ} \mathrm{C}$ for 24 hours does not further affect the immune response, compared to $36^{\circ} \mathrm{C}$

\section{Abbreviations}

APACHE: Acute Physiology and Chronic Health Evaluation; ELISA: enzymelinked immunosorbent assay; HLA-DR: human leukocyte antigen-DR; ICU: intensive care unit; IL: interleukin; LPS: lipopolysaccharide;

LTA: lipoteicoic acid; MCP: monocyte chemotactic protein; MESF: molecules of equivalent soluble fluorochrome; MIP: macrophage inflammatory proteins; ROSC: return of spontaneous circulation; SAPS: Simplified Acute Physiology Score; SIRS: systemic inflammatory response syndrome; TNF-a: tumor necrosis factor; TLR: toll-like receptor; TTM: Temperature Target Management.

\section{Competing interests}

All authors declare no financial or other potential conflicts of interest.

\section{Authors' contributions}

CB designed the study, executed the study protocol and collected the data, analysed the data and wrote the first draft of the manuscript. NJ designed the study, analysed the data and wrote the first draft of the manuscript. JH designed the study and critically revised the manuscript. AT handled the Luminex and ELISA measurements and critically revised the manuscript. EvL handled the HLA-DR measurements study and critically revised the manuscript. MS contributed to the conception of the study, the interpretation of the data and critically revised the manuscript. MV contributed to the conception of the study, the interpretation of the data and critically revised the manuscript. All authors gave their final approval of the version to be published and agreed to be accountable for all aspects of the work in ensuring that questions related to the accuracy or integrity of any part of the work are appropriately investigated and resolved. All authors read and approved the final manuscript.

\section{Disclosure of funding}

NWO ZonMW Clinical Fellowship to Dr. N. P. Juffermans. (Project number: 90700269). Funding did not influence the design, data collection, analysis, data interpretation, writing or the decision to submit the manuscript for publication.

\section{Author details}

'Laboratory of Experimental Intensive Care and Anaesthesiology, Academic Medical Center, University of Amsterdam, Meibergdreef 9, 1105 AZ, Amsterdam, Netherlands. ${ }^{2}$ Department of Intensive Care, Academic Medical Center, University of Amsterdam, Meibergdreef 9, 1105 AZ, Amsterdam, Netherlands. ${ }^{3}$ Department of Experimental Immunology, Academic Medical Center, University of Amsterdam, Meibergdreef 9, $1105 \mathrm{AZ}$, Amsterdam, Netherlands. ${ }^{4}$ Laboratory of Experimental Intensive Care and Anaesthesiology (L.E.I.C.A.) / Department of Intensive Care Medicine, Academic Medical Center, Room MO-210, Meibergdreef 9, 1105 AZ, Amsterdam, Netherlands.

Received: 6 March 2014 Accepted: 26 June 2014

Published: 30 July 2014

\section{References}

1. Mild therapeutic hypothermia to improve the neurologic outcome after cardiac arrest. N Engl J Med 2002, 346:549-556.

2. Nolan JP, Deakin CD, Soar J, Bottiger BW, Smith G, European Resuscitation C: European Resuscitation Council guidelines for resuscitation 2005. Section 4. Adult advanced life support. Resuscitation 2005, 67:S39-S86.

3. Rees K, Beranek-Stanley M, Burke M, Ebrahim S: Hypothermia to reduce neurological damage following coronary artery bypass surgery. Cochrane Database Syst Rev 2001, 1:CD002138.

4. Rao V, Christakis GT, Weisel RD, Ivanov J, Peniston CM, Ikonomidis JS, Shirai T: Risk factors for stroke following coronary bypass surgery. J Card Surg 1995, 10:468-474

5. Martin TD, Craver JM, Gott JP, Weintraub WS, Ramsay J, Mora CT, Guyton RA: Prospective, randomized trial of retrograde warm blood cardioplegia: myocardial benefit and neurologic threat. Ann Thorac Surg 1994, 57:298-302. discussion 302-304.

6. Zeiner A, Holzer M, Sterz F, Schörkhuber W, Eisenburger P, Havel C, Kliegel A, Laggner AN: Hyperthermia after cardiac arrest is associated with an unfavorable neurologic outcome. Arch Intern Med 2001, 161:2007-2012. 
7. Schortgen F, Clabault K, Katsahian S, Devaquet J, Mercat A, Deye N, Dellamonica J, Bouadma L, Cook F, Beji O, Brun-Buisson C, Lemaire F: Fever control using external cooling in septic shock: a randomized controlled trial. Am J Respir Crit Care Med 2012, 185:1088-1095.

8. Meybohm P, Gruenewald M, Zacharowski KD, Albrecht M, Lucius R, Fosel N Hensler J, Zitta K, Bein B: Mild hypothermia alone or in combination with anesthetic post-conditioning reduces expression of inflammatory cytokines in the cerebral cortex of pigs after cardiopulmonary resuscitation. Crit Care 2010, 14:R21.

9. Sarcia PJ, Scumpia PO, Moldawer LL, DeMarco VG, Skimming JW: Hypothermia induces interleukin-10 and attenuates injury in the lungs of endotoxemic rats. Shock 2003, 20:41-45.

10. Beurskens CJ, Aslami H, Kuipers MT, Horn J, Vroom MB, van Kuilenburg AB, Roelofs JJ, Schultz MJ, Juffermans NP: Induced hypothermia is protective in a rat model of pneumococcal pneumonia associated with increased adenosine triphosphate availability and turnover. Crit Care Med 2012, 40:919-926.

11. Lim CM, Kim MS, Ahn JJ, Kim MJ, Kwon Y, Lee I, Koh Y, Kim DS, Kim WD: Hypothermia protects against endotoxin-induced acute lung injury in rats. Intensive Care Med 2003, 29:453-459.

12. Taniguchi $T$, Kanakura $H$, Takemoto $Y$, Yamamoto $K$ : Effects of hypothermia on mortality and inflammatory responses to endotoxin-induced shock in rats. Clin Diagn Lab Immunol 2003, 10:940-943

13. Chu SJ, Perng WC, Hung CM, Chang DM, Lin SH, Huang KL: Effects of various body temperatures after lipopolysaccharide-induced lung injury in rats. Chest 2005, 128:327-336.

14. Chin JY, Koh Y, Kim MJ, Kim HS, Kim WS, Kim DS, Kim WD, Lim CM: The effects of hypothermia on endotoxin-primed lung. Anesth Analg 2007, 104:1171-1178. tables of contents.

15. Kira S, Daa T, Kashima K, Mori M, Noguchi T, Yokoyama S: Mild hypothermia reduces expression of intercellular adhesion molecule-1 (ICAM-1) and the accumulation of neutrophils after acid-induced lung injury in the rat. Acta Anaesthesiol Scand 2005, 49:351-359.

16. L'Her E, Amerand A, Vettier A, Sebert P: Effects of mild induced hypothermia during experimental sepsis. Crit Care Med 2006, 34:2621-2623.

17. Kluger MJ, Kozak W, Conn CA, Leon LR, Soszynski D: The adaptive value of fever. Infect Dis Clin North Am 1996, 10:1-20.

18. Jiang Q, Cross AS, Singh IS, Chen TT, Viscardi RM, Hasday JD: Febrile core temperature is essential for optimal host defense in bacterial peritonitis. Infect Immun 2000, 68:1265-1270.

19. Torossian A, Ruehlmann S, Middeke M, Sessler DI, Lorenz W, Wulf HF, Bauhofer A: Mild preseptic hypothermia is detrimental in rats. Crit Care Med 2004, 32:1899-1903.

20. Su F, Nguyen ND, Wang Z, Cai Y, Rogiers P, Vincent JL: Fever control in septic shock: beneficial or harmful? Shock 2005, 23:516-520.

21. Bernheim HA, Kluger MJ: Fever: effect of drug-induced antipyresis on survival. Science 1976, 193:237-239.

22. Klastersky J, Kass EH: Is suppression of fever or hypothermia useful in experimental and clinical infectious diseases? J Infect Dis 1970, 121:81-86.

23. Kimura A, Sakurada S, Ohkuni H, Todome Y, Kurata K: Moderate hypothermia delays proinflammatory cytokine production of human peripheral blood mononuclear cells. Crit Care Med 2002, 30:1499-1502.

24. Biggar WD, Bohn DJ, Kent G, Barker C, Hamilton G: Neutrophil migration in vitro and in vivo during hypothermia. Infect Immun 1984, 46:857-859.

25. Biggar WD, Barker C, Bohn D, Kent G: Partial recovery of neutrophil functions during prolonged hypothermia in pigs. $J$ Appl Physiol (1985) 1986, 60:1186-1189.

26. Adrie C, Adib-Conquy M, Laurent I, Monchi M, Vinsonneau C, Fitting C, Fraisse F, Dinh-Xuan AT, Carli P, Spaulding C, Dhainaut JF, Cavaillon JM: Successful cardiopulmonary resuscitation after cardiac arrest as a "sepsis-like" syndrome. Circulation 2002, 106:562-568.

27. Nielsen N, Wetterslev J, Cronberg T, Erlinge D, Gasche Y, Hassager C, Horn J, Hovdenes J, Kjaergaard J, Kuiper M, Pellis T, Stammet P, Wanscher M, Wise MP, Aneman A, Al-Subaie N, Boesgaard S, Bro-Jeppesen J, Brunetti I, Bugge JF, Hingston CD, Juffermans NP, Koopmans M, Kober L, Langorgen J, Lilja G, Moller JE, Rundgren M, Rylander C, Smid O, Werer C, Winkel P, Friberg H, et al: Targeted temperature management at 33 degrees $C$ versus 36 degrees $C$ after cardiac arrest. N Engl J Med 2013, 369:2197-2206.

28. Clifton GL, Miller ER, Choi SC, Levin HS, McCauley S, Smith KR Jr, Muizelaar JP, Wagner FC Jr, Marion DW, Luerssen TG, Chesnut RM, Schwartz M: Lack of effect of induction of hypothermia after acute brain injury. $N$ Engl J Med 2001, 344:556-563.
29. Clifton GL, Valadka A, Zygun D, Coffey CS, Drever P, Fourwinds S, Janis LS, Wilde E, Taylor P, Harshman K, Conley A, Puccio A, Levin HS, McCauley SR, Bucholz RD, Smith KR, Schmidt JH, Scott JN, Yonas H, Okonkwo DO: Very early hypothermia induction in patients with severe brain injury (the National Acute Brain Injury Study: Hypothermia II): a randomised trial. Lancet Neurol 2011, 10:131-139.

30. Qiu W, Zhang Y, Sheng H, Zhang J, Wang W, Liu W, Chen K, Zhou J, Xu Z: Effects of therapeutic mild hypothermia on patients with severe traumatic brain injury after craniotomy. J Crit Care 2007, 22:229-235.

31. Polderman KH, Tjong Tjin Joe R, Peerdeman SM, Vandertop WP, Girbes AR: Effects of therapeutic hypothermia on intracranial pressure and outcome in patients with severe head injury. Intensive Care Med 2002, 28:1563-1573.

32. Kamps M, Bisschops L, van der Hoeven JG, Hoedemaekers CW: Hypothermia does not increase the risk of infection: a case control study. Crit Care 2011, 15:R48.

33. Qiu W, Shen $H$, Zhang $Y$, Wang W, Liu W, Jiang Q, Luo M, Manou M: Noninvasive selective brain cooling by head and neck cooling is protective in severe traumatic brain injury. J Clin Neurosci 2006, 13:995-1000.

34. Geurts M, Macleod MR, Kollmar R, Kremer PH, van der Worp HB: Therapeutic hypothermia and the risk of infection: a systematic review and meta-analysis. Crit Care Med 2014, 42:231-242.

35. Bisschops LL, Hoedemaekers CW, Mollnes TE, van der Hoeven JG: Rewarming after hypothermia after cardiac arrest shifts the inflammatory balance. Crit Care Med 2012, 40:1136-1142

36. Bekeredjian-Ding I, Jego G: Toll-like receptors-sentries in the B-cell response. Immunology 2009, 128:311-323.

37. Monneret G, Elmenkouri N, Bohe J, Debard AL, Gutowski MC, Bienvenu J, Lepape A: Analytical requirements for measuring monocytic human lymphocyte antigen DR by flow cytometry: application to the monitoring of patients with septic shock. Clin Chem 2002, 48:1589-1592.

38. Lukaszewicz AC, Grienay M, Resche-Rigon M, Pirracchio R, Faivre V, Boval B, Payen D: Monocytic HLA-DR expression in intensive care patients: interest for prognosis and secondary infection prediction. Crit Care Med 2009, 37:2746-2752.

39. Qadan M, Gardner SA, Vitale DS, Lominadze D, Joshua IG, Polk HC Jr: Hypothermia and surgery: immunologic mechanisms for current practice. Ann Surg 2009, 250:134-140.

40. Arts D, de Keizer N, Scheffer GJ, de Jonge E: Quality of data collected for severity of illness scores in the Dutch National Intensive Care Evaluation (NICE) registry. Intensive Care Med 2002, 28:656-659.

41. Skrzeczynska-Moncznik J, Bzowska M, Loseke S, Grage-Griebenow E, Zembala M, Pryjma J: Peripheral blood CD14high CD16+ monocytes are main producers of IL-10. Scand J Immunol 2008, 67:152-159.

42. Cros J, Cagnard N, Woollard K, Patey N, Zhang SY, Senechal B, Puel A, Biswas SK, Moshous D, Picard C, Jais JP, D'Cruz D, Casanova JL, Trouillet C, Geissmann F: Human CD14dim monocytes patrol and sense nucleic acids and viruses via TLR7 and TLR8 receptors. Immunity 2010, 33:375-386.

43. Fumeaux T, Pugin J: Role of interleukin-10 in the intracellular sequestration of human leukocyte antigen-DR in monocytes during septic shock. Am J Respir Crit Care Med 2002, 166:1475-1482.

44. Perbet S, Mongardon N, Dumas F, Bruel C, Lemiale V, Mourvillier B, Carli P, Varenne O, Mira JP, Wolff M, Cariou A: Early-onset pneumonia after cardiac arrest: characteristics, risk factors and influence on prognosis. Am J Respir Crit Care Med 2011, 184:1048-1054.

45. Rello J, Valles J, Jubert P, Ferrer A, Domingo C, Mariscal D, Fontanals D, Artigas A: Lower respiratory tract infections following cardiac arrest and cardiopulmonary resuscitation. Clin Infect Dis 1995, 21:310-314.

46. Tsai MS, Chiang WC, Lee CC, Hsieh CC, Ko PC, Hsu CY, Su CP, Chen SY, Chang WT, Yuan A, Ma MH, Chen SC, Chen WJ: Infections in the survivors of out-ofhospital cardiac arrest in the first 7 days. Intensive Care Med 2005, 31:621-626.

47. Polderman $\mathrm{KH}$, Herold I: Therapeutic hypothermia and controlled normothermia in the intensive care unit: practical considerations, side effects, and cooling methods. Crit Care Med 2009, 37:1101-1120.

\section{doi:10.1186/cc14002}

Cite this article as: Beurskens et al:: Cardiac arrest patients have an impaired immune response, which is not influenced by induced hypothermia. Critical Care 2014 18:R162. 